\title{
Toward an artificial sensory feedback system for prosthetic mobility rehabilitation: Examination of sensorimotor responses
}

\author{
Aman Sharma, MHSc; ${ }^{1-2}$ Ricardo Torres-Moreno, PhD; ${ }^{3-4}$ Karl Zabjek, PhD; ${ }^{2,4}$ Jan Andrysek, PhD ${ }^{1-2 *}$ \\ ${ }^{1}$ Institute for Biomaterials and Biomedical Engineering, University of Toronto, Toronto, Ontario, Canada; ${ }^{2}$ Bloorview \\ Research Institute and ${ }^{3}$ Clinical Technology Department, Holland Bloorview Kids Rehabilitation Hospital, Toronto, \\ Ontario, Canada; ${ }^{4}$ Department of Physical Therapy, University of Toronto, Toronto, Ontario, Canada
}

\begin{abstract}
People with lower-limb amputation have reduced mobility due to loss of sensory information, which may be restored by artificial sensory feedback systems built into prostheses. For an effective system, it is important to understand how humans sense, interpret, and respond to the feedback that would be provided. The goal of this study was to examine sensorimotor responses to mobility-relevant stimuli. Three experiments were performed to examine the effects of location of stimuli, frequency of stimuli, and means for providing the response. Stimuli, given as vibrations, were applied to the thigh region, and responses involved leg movements. Sensorimotor reaction time (RT) was measured as the duration between application of the stimulus and initiation of the response. Accuracy of response was also measured. Overall average RTs for one response option were $0.808+/-0.142 \mathrm{~s}$, and response accuracies were $>90 \%$. Higher frequencies $(220 \mathrm{vs} 140 \mathrm{~Hz}$ ) of vibration stimulus provided in anterior regions of the thigh produced the fastest RTs. When participants were presented with more than one stimulus and response option, RTs increased. Findings suggest that long sensorimotor responses may be a limiting factor in the development of an artificial feedback system for mobility rehabilitation applications; however, feed-forward techniques could potentially help to address these limitations.
\end{abstract}

Key words: amputation, biofeedback, lower-limb amputation, mobility rehabilitation, proprioception, reaction time, sensorimotor responses, sensory feedback, transfemoral, vibration.

\section{INTRODUCTION}

Individuals with lower-limb amputation (LLA) typically have a reduced ability, not only to control their artificial limb, but also to sense what the leg is doing, since parts of the peripheral sensory system are no longer present. One aspect of this relates to the information that, in nondisabled individuals, is provided via the mechanoreceptors in the foot and muscles in response to the loading of the body, thus making gait and balance functions possible [1]. A second aspect relates to proprioception, or the awareness of one's body position and movement in space, which enables humans to achieve complex motor activity and interact and move purposively within their physical surroundings [2]. Proprioception involves a multicomponent sensory system that includes contributions from the vestibular and somatosensory system, as well as a variety of proprioceptors in the muscles and joints [3-4]. In the case of individuals with LLA, the loss of a limb involves the loss of proprioceptors within the affected part of the

\footnotetext{
Abbreviations: ANOVA $=$ analysis of variance, $\mathrm{BMI}=$ body mass index, FFT $=$ Fast Fourier Transform, LLA = lower-limb amputation, $\mathrm{RT}=$ reaction time.

*Address all correspondence to Jan Andrysek, PhD; Bloorview Research Institute, Holland Bloorview Kids Rehabilitation Hospital, 150 Kilgour Rd, Toronto, Ontario M4G 1R8, Canada; 416-425-6220, ext 3524; fax: 416-425-1634. Email: jandrysek@hollandbloorview.ca http://dx.doi.org/10.1682/JRRD.2013.07.0164
} 
lower limb [5-6]. While the provision of an artificial limb serves many important functions to facilitate the rehabilitation of movement and mobility, current systems do not provide an artificial means to substitute for the losses in proprioception or information about the loading of the lower limbs. To compensate, individuals with LLA rely on alternate information and senses, such as the kinetic interactions of the residuum at the prosthetic socket, vision, and hearing in order to maintain upright posture and safely and effectively execute complex mobility tasks [7-11]. However, despite these compensatory mechanisms, individuals with LLA have slower and less efficient gait [12], poorer balance and postural control, increased risk of loss of balance resulting in falls $[8-9,13]$, and in general, the need for prolonged rehabilitation periods to enable a satisfactory level of functional mobility.

One way of addressing these challenges that individuals with LLA currently face is to attempt to restore sensory loss by providing artificial sensory feedback. A small number of studies have investigated providing sensory feedback to individuals with LLA in order to improve balance and postural control. Recently, Rusaw et al. demonstrated that prosthetic users' postural control may be improved by utilizing feedback applied unilaterally on the side of the prosthesis [8]. In similar studies, Fan et al. used a system that incorporated pneumatic balloons to provide mechanical stimulation to the residual limb $[1,14]$, and more recently, Wentink et al. used vibratory stimuli in order to improve the speed with which the stimuli can be applied [15]. Wentink et al. further utilized the Visual Ana$\log$ Scale to investigate the effects of stimulus characteristics as they relate to an individual's ability to respond [15]. This is important since the feasibility of an artificial feedback system for individuals with LLA depends in large part on how effectively the feedback information can be utilized.

Developing an understanding of the ways by which a participant perceives and responds to specific stimuli, or the sensorimotor response, will help to inform how artificial feedback systems may be most effectively utilized in lower-limb prostheses. One important aspect is the time it takes for an individual to sense and accurately respond to a stimulus. For relatively static activities such as standing postural control, which has to date been the primary focus of investigation for lower-limb artificial feedback systems $[1,8,14]$, the requirements are not as stringent as for more dynamic activities such as walking. This is because standing requires slow and low-amplitude postural control adjustments in contrast to the highly dynamic characteristics of gait. Hence, in order to gain a better understanding of how artificial feedback may be applied to prosthetic mobility rehabilitation, it is important to examine the sensorimotor response of the lower limbs.

The aim of this study was to gain a better understanding of how individuals with LLA respond to sensory feedback information provided to the lower limb. The objective was to evaluate voluntary reaction times (RTs) and accuracies following the introduction of a vibratory stimulus to the lower limb and examine the effect of location, number of stimuli, properties of the stimuli (frequency), and type of response (by movement of hand or using a leg). We hypothesized that (1) stimulus location, (2) stimulus frequency, (3) number of stimuli, and (4) whether responding with the hand or leg would have an effect on RT and accuracy. We also hypothesized that (5) distinguishing two stimuli that were farther apart from each other on the skin would result in shorter RTs and higher accuracy, as would (6) two stimuli with more dissimilar frequencies.

\section{METHODS}

\section{Participants}

Two convenience samples, one of 12 nondisabled participants and one of 3 participants with transfemoral amputation, were recruited for this study. All of the participants were recruited at Holland Bloorview Kids Rehabilitation Hospital in Toronto, Canada. Nondisabled participants consisted of staff and students at the hospital deemed to have no known neuromusculoskeletal-related health issues. The participants with amputation were clients recruited from the Clinical Technology Department at the hospital. Participants with amputation were included on the basis that they had no affiliated health issues, including neurological disease, diabetes, and peripheral vascular disease, and that their residual limbs were free from burns, scars, unhealed wounds, blisters, or skin problems. All participants were required to effectively communicate in English. To limit potential confounding factors due to physiological development, participation was limited to adults (age $\geq 16 \mathrm{yr}$ ).

\section{Equipment}

Commercially available vibrotactile motors, similar to those used in cellular telephones for vibrations, were used 
due to their small size and quick actuation RTs [1]. The motors (model 310-101) were obtained from Precision Microdrives Inc (London, England) (Figure 1). These motors have an offset mass, causing a centripetal acceleration and force that are perpendicular to the axis of rotation. When attached to the skin as was done in this study, the action of the motor produces shear forces. The amplitude of the centripetal accelerations is linearly proportional to the speed of the motor and frequency. Each motor was preconfigured and calibrated using a custom-designed Fast Fourier Transform (FFT) LabVIEW program (National Instruments Corp; Austin, Texas) and an ADXL 335 accelerometer (Dimension Engineering; Akron, Ohio) to operate at the vibratory frequencies required for the study. An Arduino Mega 2560 (Sparkfun Electronics; Boulder, Colorado) was used as the main microprocessor unit, with $\mathrm{N}$ type metal-oxide-semiconductor field-effect transistors used to power and control the vibrotactile motors that provided the stimuli. Motors were strapped to the accelerometer and fine-tuned using the FFT program to determine the relationship between voltage and vibration frequency.

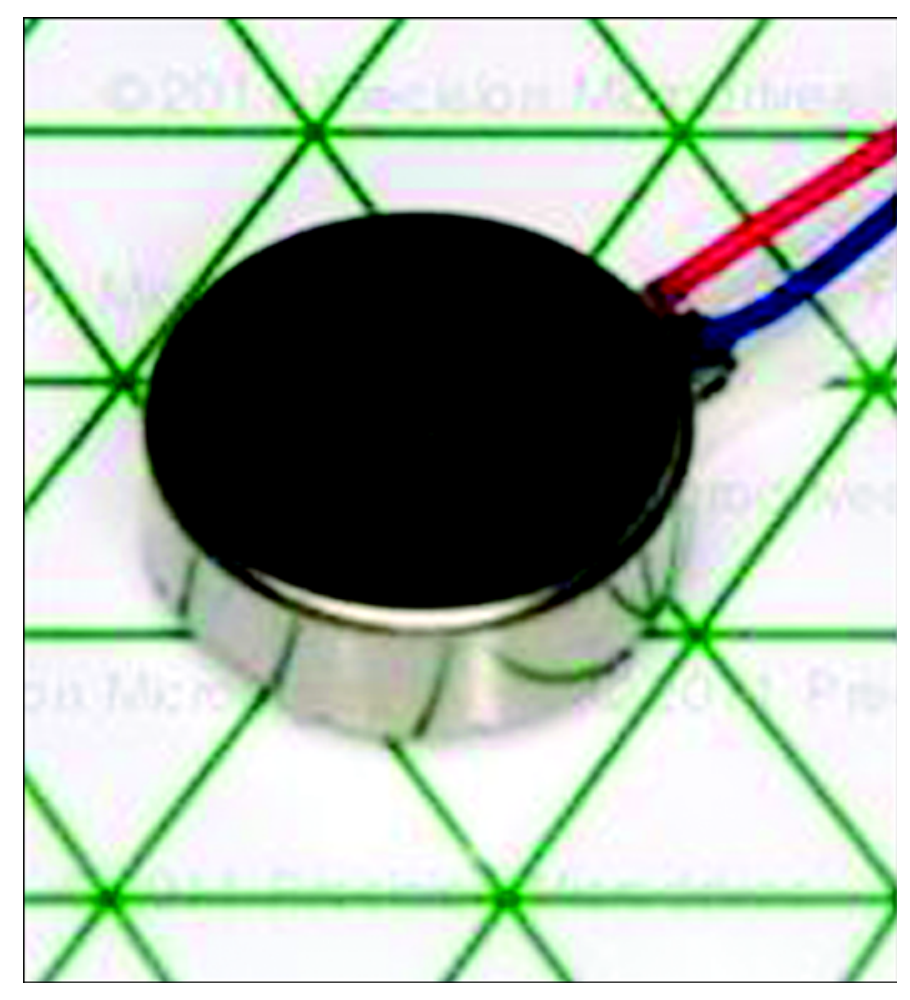

Figure 1.

Vibratory motor in detail.
Figure 2 shows a custom rig designed to house the participant's leg, sensory feedback system, and push buttons. The rig consisted of a rigid platform for participants to rest their dominant-side leg. Push buttons were obtained (Buddy Button Gator Green, Bridges Canada Inc;

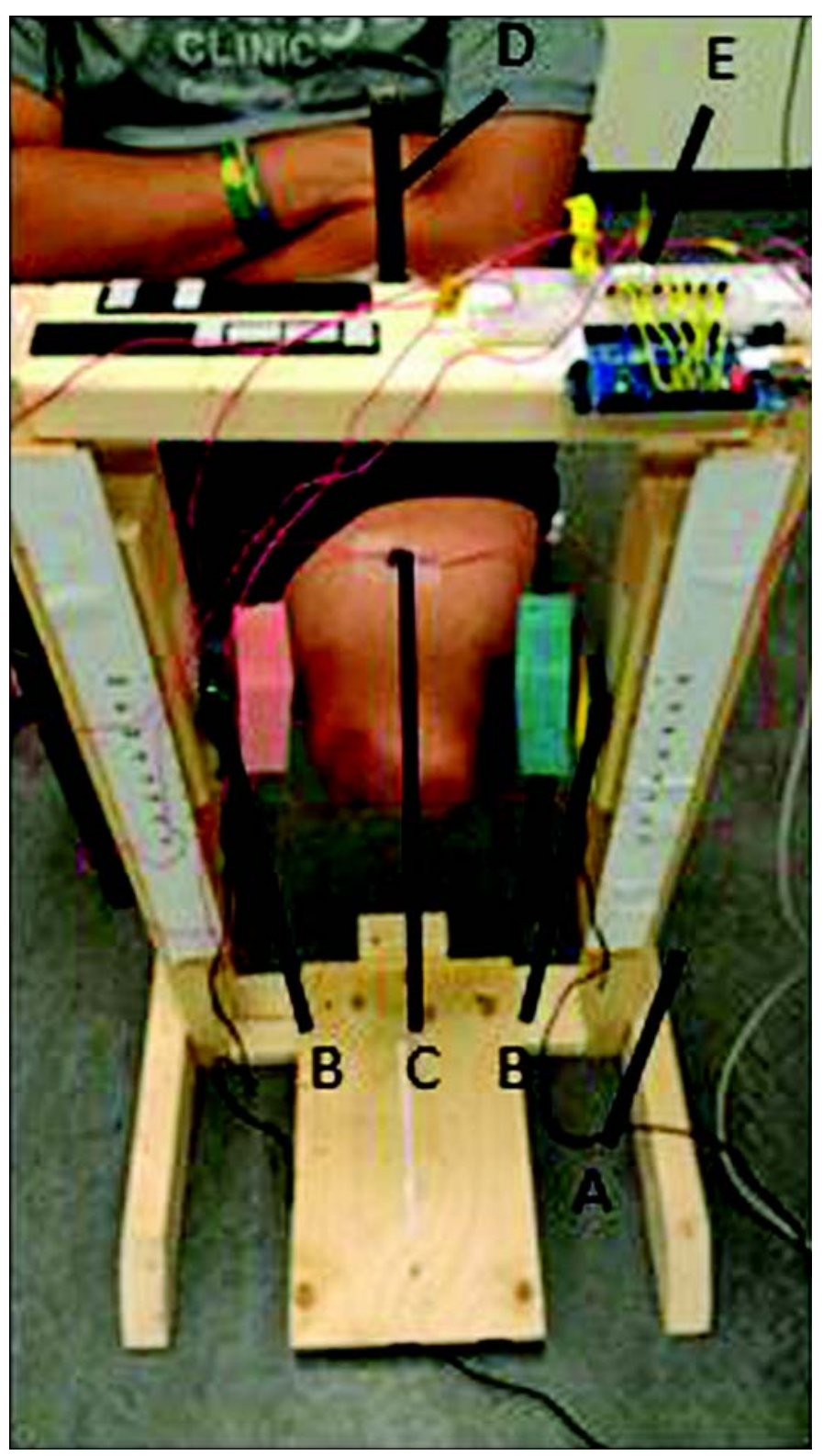

Figure 2.

Custom rig designed to hold participant's residual limb and house push buttons and microprocessor. $A=$ custom rig, $B=$ push button and soft sponge, $C=$ vibratory motor, $D=$ laser pointer, E = Arduino Mega 2560 microprocessor unit (Sparkfun Electronics; Boulder, Colorado). 
Mississiauga, Canada), and used to record the RTs of response movements. The push buttons were affixed to a custom wooden rig using Velcro and were adjustable to the height of the participant's knee. Soft sponges (similar to those used for cleaning dishes) were used to cushion the impact between the participant's leg and push button. Pilot testing was conducted to ensure the sponges did not adversely affect RTs.

\section{Protocol}

Participant characteristics were recorded, which included body mass index (BMI), height, age, and shoe size. For the nondisabled participants, the distance from the greater trochanter to the lateral femoral condyle, distance from the lateral femoral condyle to the ankle, and knee width were measured. For the participants with amputation, the distance from the end of the residual limb to the greater trochanter was measured. Three experiments were performed in this study that looked at RTs of individuals to various vibratory stimuli and conditions. Testing was done on the lower limb, since the work aims to address a lower-limb artificial feedback system for mobility rehabilitation applications. Specifically, participants with transfemoral amputation were targeted, since they typically face greater mobility challenges than individuals with more distal amputations [16-17]. For a person with transfemoral amputation, a prosthesis interfaces via a prosthetic socket at the thigh region of the leg, thus making this a potentially practical location for providing sensory stimulation. Hence, the thigh was the chosen location to apply the vibratory motors in this study. Similarly, responses were restricted to the movements of the leg and specifically the thigh segment (with the exception of the hand experiments), in consideration of the fact that musculature at the hip joint provides the primary means for controlling a transfemoral prosthesis during mobility. Participants wore shorts and vibratory motors were adhered using double-sided tape directly to the unshaven skin. All participants were seated (Figure 2). Testing was done on the dominant leg for nondisabled subjects. This was determined by having participants kick a rolling soccer ball and noting which leg they used first. For the participants with transfemoral amputation, testing was done with the amputated limb since, as explained earlier, this is where an artificial sensory feedback system would most likely be applied as part of a prosthesis. Data collection occurred during a single session of approximately $2 \mathrm{~h}$ in duration per participant.
Short rests $(<5 \mathrm{~min})$ were provided between sets of trials and experiments.

\section{Experiment 1}

The motors were affixed on the thigh (Figure 3). The first motor was placed on the anterior of the thigh midway between the greater trochanter and lateral femoral condyle or on the distal end of the residual limb in the case of the participants with amputation. Using the circumference of the thigh, subsequent motors were placed one-fourth of the total circumference equidistant around the thigh, $90^{\circ}$ apart.

During testing, one of three frequencies $(140,180$, or $220 \mathrm{~Hz}$ ) was applied randomly to one of the four locations, and the participant was instructed to push the push button by moving his or her leg as quickly as possible in the lateral direction upon detecting a vibratory stimulus. A laser pointer ensured that participants lined up their leg in the same position between each trial (Figure 2). A total of 36 random trials were conducted for each iteration of the experiment ( 3 frequencies $\times 4$ locations repeated 3 times).

The experiment was repeated a second time, but instead of responding with leg movement, participants used their hand. For this, participants were comfortably seated at a table and the push button was placed on the table directly in front of the participant about $2 \mathrm{~cm}$ from their dominant hand. RT was assessed as the time between the onset of the stimulus on the thigh and the movement of the hand to depress the button.

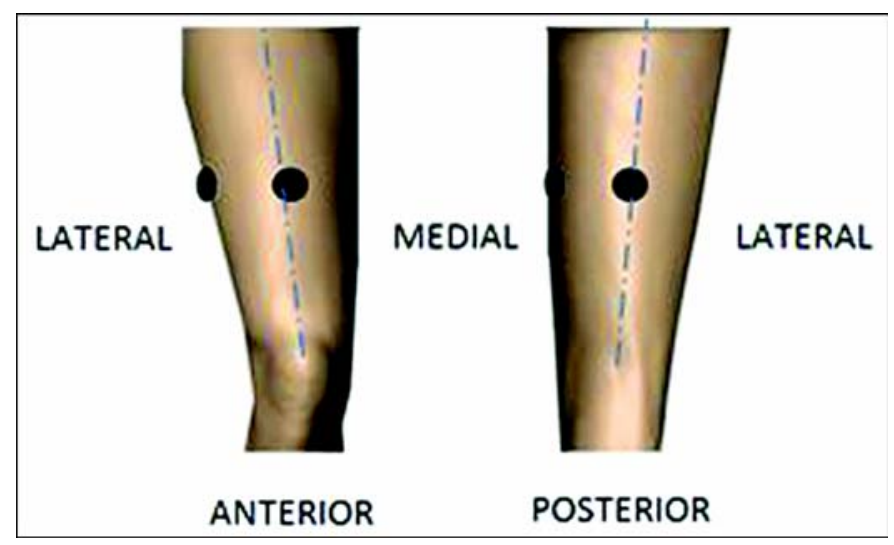

Figure 3.

Motor placement on thigh depicted by black circles for experiments 1 and 2 . 


\section{Experiment 2}

In the second experiment, participants were asked to respond to two stimuli delivered by a single motor. The motor placement on the thigh was the same as in experiment 1 . Participants were given a vibratory stimulation for $1.5 \mathrm{~s}$, followed by a $1.5 \mathrm{~s}$ pause, and then a second vibratory stimulation at a different frequency. They were asked to respond as quickly as possible to whether they believed the second stimulation was a higher or lower frequency than the first stimulation that they felt by either pressing the right button (if it was higher) or left button (if it was lower). Various frequency permutations (140 vs $180 \mathrm{~Hz}, 140$ vs $220 \mathrm{~Hz}, 180$ vs $140 \mathrm{~Hz}, 180$ vs $220 \mathrm{~Hz}$, 220 vs $140 \mathrm{~Hz}$, and $220 \mathrm{vs} 180 \mathrm{~Hz}$ ) were tested and repeated for all four locations, for which the participant was given a priori knowledge of the location of the expected stimulation. RTs, as well as their choice (i.e., which button they pressed), were recorded for each trial. A total of 48 trials (4 locations $\times 6$ frequency permutations repeated 2 times) were collected for this experiment for each participant.

\section{Experiment 3}

In experiment 3 , the motors were repositioned on just the anterior region of the thigh. This experiment is a modified version of Wentink et al.'s experiment 2, where their results affirmed that the anterior region had greater sensitivity and specificity than the posterior region [15]. Seven motors were spaced $3 \mathrm{~cm}$ apart along the midline of the anterior thigh. A baseline reference motor was centered with three motors in proximal and distal directions (Figure 4). P9 indicates the most proximal motor, while D9 indicates the most distal motor. Participants were told that they would always feel the reference motor vibrate first, followed by any of the other six motors. They were asked to respond as quickly as possible to whether they believed the second motor that vibrated was more distal or more proximal to the central motor, by pushing a designated button corresponding to their selection (right button if it was more distal, left button if it was more proximal). RTs and responses were recorded for each trial. A total of 18 random trials (6 motor locations repeated 3 times) were collected for each participant.

\section{Data Analysis}

RTs were recorded and captured using a customized LABVIEW program (National Instruments Corp) interfaced with the Arduino Mega 2560 microprocessor (Spark-

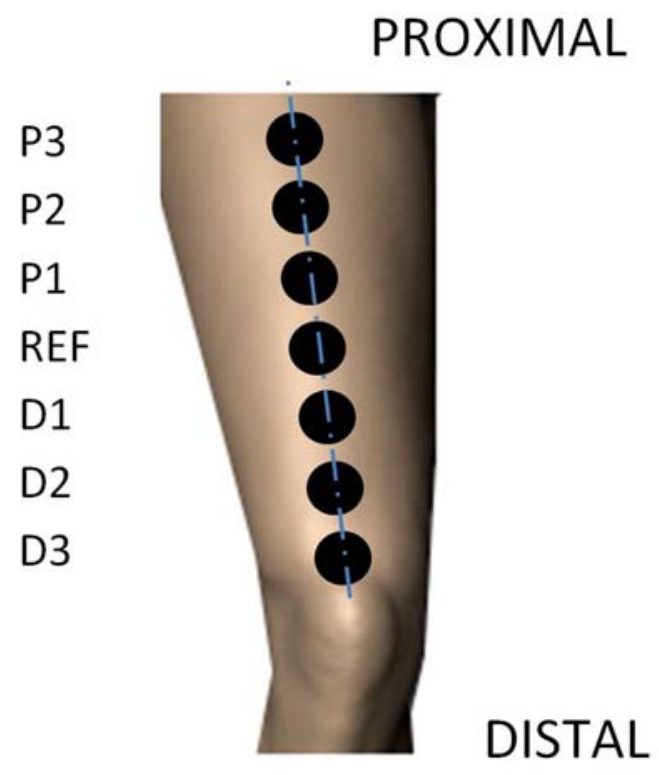

Figure 4.

Motor placement on anterior thigh depicted by black circles for experiment 3. Labeling refers to distal (D) or proximal $(P)$ location from reference (Ref) motor. Numerical value represents distance in centimeters.

fun Electronics). Data were exported as ASCII text files to Excel (Microsoft Corp; Redmond, Washington) and restructured to an SPSS format. Statistical analysis was performed using SPSS version 20 (IBM Corp; Armonk, New York). To test our hypotheses as stated previously, a repeated-measures analysis of variance (ANOVA) was performed for each of the experiments for the nondisabled participants. Statistical significance was determined using a critical alpha level of 0.05 for all primary analyses. Pairwise comparisons with Bonferroni adjustment were used to identify significance in the dependent variable test conditions. Two levels of conditions were set for the repeatedmeasures ANOVA setup: baseline (control) and using the hand to respond. Four levels of location were set: anterior, lateral, posterior, and medial regions. Three levels of frequencies were set: 140, 180, and $220 \mathrm{~Hz}$. Due to the small sample size, descriptive statistics were used for the data of the participants with amputation.

\section{RESULTS}

The nondisabled participants ( 7 male, 5 female) had a mean \pm standard deviation age of $27 \pm 2 \mathrm{yr}$, weight of 
$69.45 \pm 17.31 \mathrm{~kg}$, height of $1.72 \pm 0.11 \mathrm{~m}$, and BMI of $23.3 \pm 1.2$. Table 1 provides characteristics of the participants with amputation.

Based on the nondisabled participants in experiment 1, the experimental conditions (leg and hand responses) were found to be significant on RTs $(F(1,11)=34.97, p<$ $0.001)$. Hand RTs $(0.568 \pm 0.029 \mathrm{~s})$ were found to be significantly shorter than the baseline leg response $(0.712 \pm$ 0.032 s) $(p<0.001)$. Location of the motors was also found to be significant on $\operatorname{RTs}(\mathrm{F}(3,33)=6.325, p=$ $0.01)$. The anterior region $(0.599 \pm 0.028 \mathrm{~s})$ was particularly shorter in RTs than the lateral $(0.657 \pm 0.032 \mathrm{~s})$ and posterior $(0.658 \pm 0.032 \mathrm{~s})$ regions. Frequency was also shown to be significant on RTs $(F(2,22)=55.09, p<$ $0.001)$. The $220 \mathrm{~Hz}$ RT $(0.584 \pm 0.025 \mathrm{~s})$ was significantly shorter than the $140 \mathrm{~Hz}$ RT $(0.711 \pm 0.034 \mathrm{~s})(p<$ $0.001)$ overall. Similarly, the $180 \mathrm{~Hz}$ RT $(0.623 \pm 0.027 \mathrm{~s})$ was significantly shorter than the $140 \mathrm{~Hz} \mathrm{RT}(p<0.001)$ and significantly longer than the $220 \mathrm{~Hz}$ RT $(p<0.001)$ overall. Figures 5 to 7 display the graphical representation of descriptive statistics for experiment 1.

In experiment 2, location of the motors was shown to be nonsignificant on $\operatorname{RTs}(F(3,33)=2.12, p=0.12)$. However, the various frequency permutations were found to be significant overall on RTs $(F(2.59,28.47)=5.09$, $p=0.01)$. In particular, RTs were significantly faster for an $80 \mathrm{~Hz}$ increase from 140 to $220 \mathrm{~Hz}(1.19 \pm 0.14 \mathrm{~s})$ than to a $40 \mathrm{~Hz}$ decrease from 180 to $140 \mathrm{~Hz}(1.47 \pm 0.15 \mathrm{~s})$ $(p=0.02)$. Participants also responded faster to a $80 \mathrm{~Hz}$ increase from 140 to $220 \mathrm{~Hz}$ than a $40 \mathrm{~Hz}$ increase from 180 to $220 \mathrm{~Hz}(1.39 \pm 0.13 \mathrm{~s})(p=0.03)$ and a $40 \mathrm{~Hz}$ decrease from 220 to $180 \mathrm{~Hz}(1.47 \pm 0.19 \mathrm{~s})(p=0.03)$. Overall, participants averaged 91 percent accuracy in correctly identifying whether the frequency of the second stimulus was higher or lower than the first for experiment 2. Analysis showed that location did not have any effect on accuracy $(F(3,33)=1.070, p=0.38)$. Similarly, pairwise comparisons of the frequency permutations showed no effect on accuracy $(p>0.05)$, signifying that changes

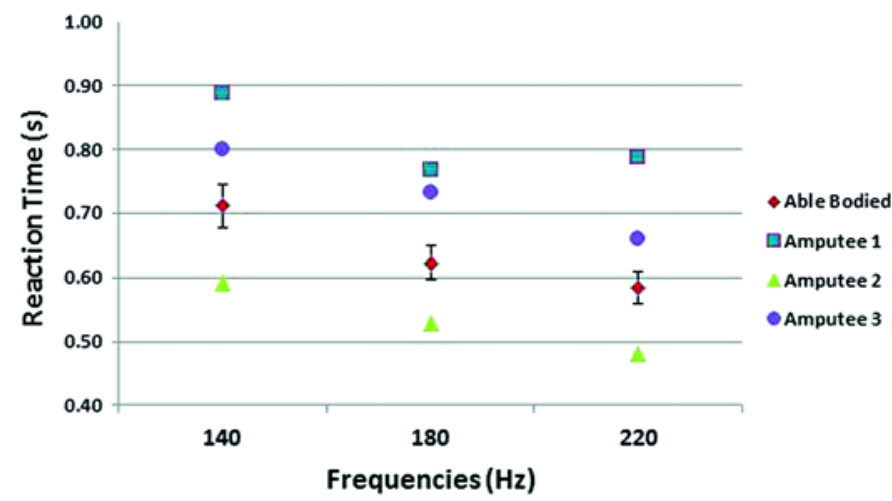

Figure 5.

Results for experiment 1 showing reaction times based on vibration frequency. Mean \pm 1 standard deviation shown for sample of nondisabled participants.

in frequency also had no effect on accuracy. Figures 8 to 9 display the descriptive statistics for experiment 2 .

In experiment 3 , there was a significant difference in leg RTs between the most distal motor (D9, $1.11 \pm 0.07 \mathrm{~s}$ ) and motor D3 $(1.47 \pm 0.01 \mathrm{~s})$, which was closer to the reference motor, with shorter RTs for the D9 motor $(p=0.01)$. Similarly, participants responded faster to the D6 motor $(1.13 \pm 0.08 \mathrm{~s})$ than the D3 motor $(p=0.01)$. Participants also reacted faster to the most proximal motor $(\mathrm{P} 9,0.94 \pm$ $0.09 \mathrm{~s})$ than the $\mathrm{P} 3$ motor $(1.49 \pm 0.15 \mathrm{~s})(p=0.05)$ and the D3 motor $(p=0.01)$. Overall, participants averaged 97.7 percent accuracy for correctly identifying whether the motor was more proximal or more distal than the reference motor. Figure 10 highlights the results for experiment 3.

\section{DISCUSSION}

Artificial sensory feedback systems in prostheses may ultimately help to improve mobility function of individuals with LLA by restoring certain elements of sensory

Table 1.

Characteristics of participants with amputation. All participants were male.

\begin{tabular}{cccccccc}
\hline Participant & $\begin{array}{c}\text { Age } \\
(\mathbf{y r})\end{array}$ & $\begin{array}{c}\text { Mass } \\
\mathbf{( k g )}\end{array}$ & $\mathbf{B M I}$ & $\begin{array}{c}\text { Height } \\
\mathbf{( m )}\end{array}$ & $\begin{array}{c}\text { Cause of } \\
\text { Amputation }\end{array}$ & $\begin{array}{c}\text { Time Since Amputation } \\
(\mathbf{y r})\end{array}$ & $\begin{array}{c}\text { Residual Limb Length } \\
(\mathbf{c m})\end{array}$ \\
\hline 1 & 20 & 72.6 & 22.9 & 1.78 & Congenital & 18 & 32 \\
2 & 22 & 86.2 & 27.2 & 1.78 & Congenital & 20 & 28 \\
3 & 35 & 60.0 & 22.0 & 1.65 & Acquired & 4 & 35 \\
\hline BMI = body mass index. & & & & & \\
\hline
\end{tabular}




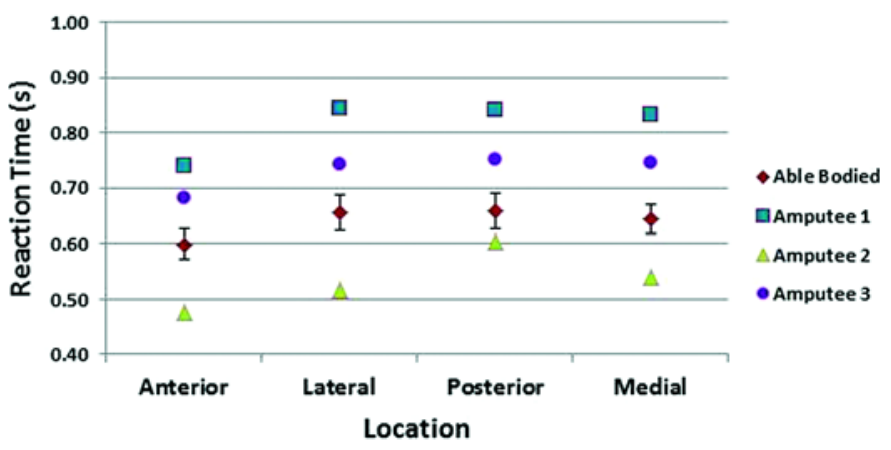

Figure 6.

Results for experiment 1 showing reaction times based on motor location. Mean \pm 1 standard deviation shown for sample of nondisabled participants. Mean shown for participants with amputation.

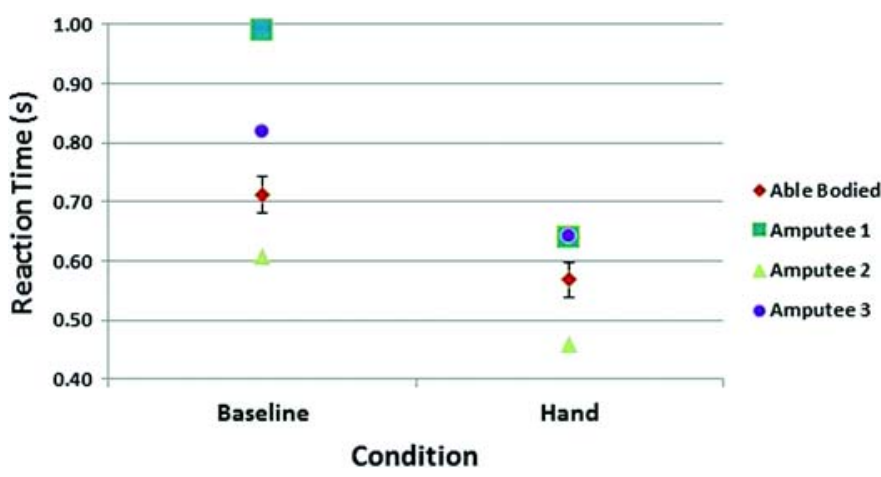

Figure 7.

Results for experiment 1 comparing reaction times at leg and hand. Mean \pm 1 standard deviation shown for sample of nondisabled participants. Mean shown for participants with amputation.

function. However, little is known about how artificial feedback should be provided and how it might be utilized by people with amputation. In this study, we investigated a number of different ways for providing sensory information to the body in order to better understand the design variables that can affect the utility and effectiveness of artificial feedback systems for mobility applications. As described in the "Introduction" section, one potential application that has previously been investigated is for postural control. However, another useful application of artificial feedback systems may be during more dynamic and challenging conditions involving mobility. For example, kinematic information about the artificial limb (posi-

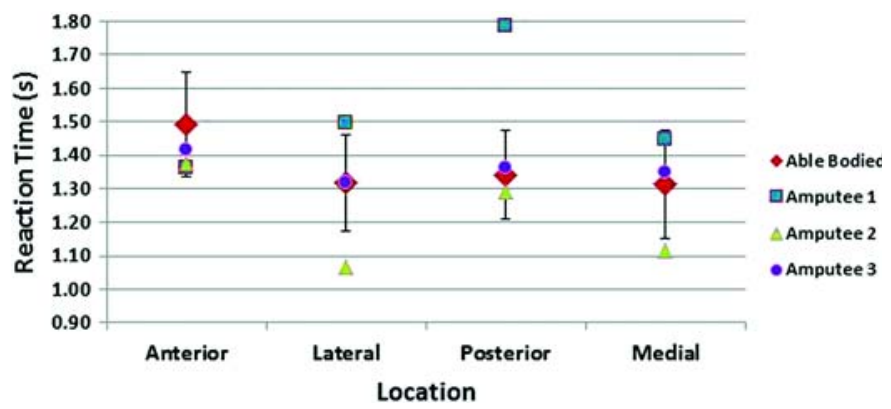

Figure 8.

Results for experiment 2 showing reaction times based on motor location. Mean \pm 1 standard deviation shown for sample of nondisabled participants. Mean shown for participants with amputation.

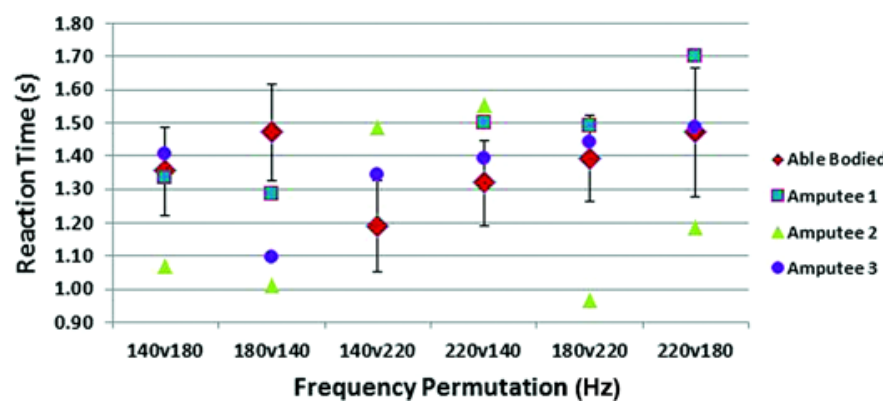

Figure 9.

Results for experiment 2 showing reaction times for various frequency permutations. Mean \pm 1 standard deviation shown for sample of nondisabled participants. Mean shown for participants with amputation.

tion and movement) may be relayed to the prosthetic user in real time to, in effect, substitute and improve their sense of proprioception. The feasibility of such an approach, however, depends on a number of factors that have not previously been investigated. Most specifically and importantly, these include the speed and accuracy with which artificial sensory feedback can be applied to elicit an appropriate response in the form of a compensatory movement.

From all of the conditions assessed, the fastest RTs achieved with the leg were around $0.6 \mathrm{~s}$ for the anterior region of the leg for the nondisabled subjects, with the individuals with LLA ranging from below 0.5 to over $0.7 \mathrm{~s}$ for the same conditions based on the results of experiment 1 . Under other conditions, including lower stimulation 
JRRD, Volume 51, Number 6, 2014

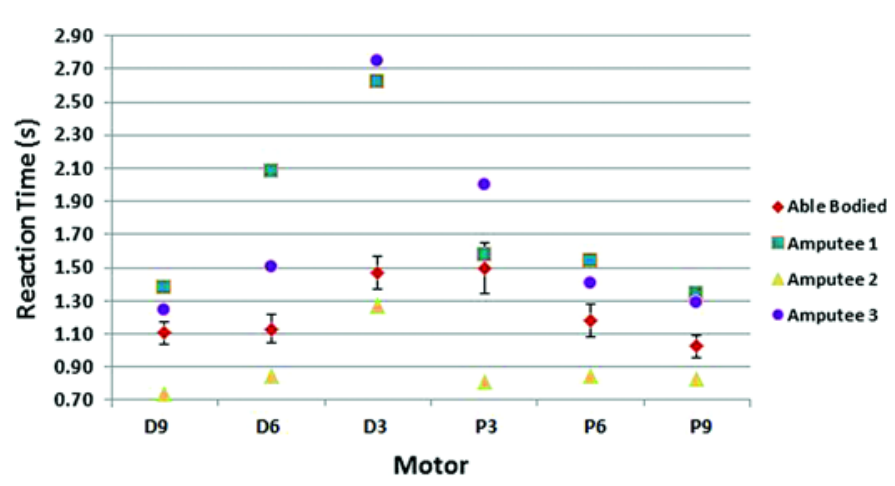

Figure 10.

Results for experiment 3 showing reaction times for various locations of motors. Mean \pm 1 standard deviation shown for sample of nondisabled participants. $\mathrm{D}=$ distal, $\mathrm{P}=$ proximal.

frequencies as well as other locations on the thigh, the RTs were higher, approaching $0.7 \mathrm{~s}$ for the nondisabled participants and up to $1.0 \mathrm{~s}$ for the participants with amputation (i.e., subject 3). For experiments 2 and 3, where the participant was required to complete a more complex task, including receiving multiple stimuli and deciding which of two buttons to correctly press, the RTs generally doubled from those measured in experiment 1 to around $1.5 \mathrm{~s}$. Given the dynamic nature of walking, these relatively long RTs are likely to present some limitations in the development application of artificial feedback systems.

During activities such as standing, relatively slow postural adjustments are needed to maintain balance with cycle times in terms of center of pressure frequency that are on the order of $0.5 \mathrm{~Hz}$ [18]. In contrast, one gait cycle time typically takes about $1.0 \mathrm{~s}$, with various subphases of the gait cycle occurring in a fraction of this time [19]. Given the relatively long RTs found in this study (i.e., $\geq 0.6 \mathrm{~s}$ ), an artificial feedback system aimed at improving postural control as has been investigated thus far has much more feasibility than one aimed at gait and mobility $[8,20-21]$. For gait and mobility applications, an artificial system as investigated here would be subject to considerable delay times, thus potentially limiting its effectiveness. The use of feed-forward techniques may be one way to address the delays, whereby information from previous phases or gait cycles are used to predict appropriate corrective actions in a subsequent gait cycle. From the results, it seems likely that such an approach may be more feasible and effective with a feedback system that is based on a single stimulus and response than one that involves dealing with two or more inputs and responses because of the lengthened RTs in the case of the latter.

Sensorimotor response measured in this study as the $\mathrm{RT}$ is a function of a number of factors, including the time it takes to sense the stimuli and transmit this information to the brain, motor planning, sending the commands to the muscles, and the ability of the muscle to respond and generate the appropriate movement. Some of the factors that have an influence on sensorimotor responses include the state of attention of arousal [22], age [23-26], and sex [27-28]. The type of stimuli also plays a role, and it has been shown that the reaction to touch (tactile stimuli) is about $155 \mathrm{~ms}$, which is comparable with auditory RTs (140-160 ms) but slower than visual RTs (180-200 ms); the main differences are attributed to the time it takes the brain to receive the signal [29].

In terms of sensing and transmitting stimulus information, we examined stimulus frequency and location. Four types of mechanoreceptors in the skin play a role in providing sensory information to the user: Merkel disks, Meissner's corpuscles, Ruffini cylinders, and Pacinian corpuscles $[15,30]$. Each of these mechanoreceptors have their own specific responsive frequency range: 5 to $15 \mathrm{~Hz}$ for Merkel disks, 20 to $50 \mathrm{~Hz}$ for Meissner's corpuscles, 15 to $400 \mathrm{~Hz}$ for Ruffini cylinders, and 60 to $400 \mathrm{~Hz}$ for Pacinian corpuscles $[15,30]$. Table 2 summarizes the various attributes associated with each of the mechanoreceptors. Various studies have confirmed that the best-detected frequency for skin vibration lies around $250 \mathrm{~Hz}$, targeting the Ruffini cylinders and Pacinian corpuscles [13,15,30 34]. The use of higher frequencies $(>200 \mathrm{~Hz})$ also have a larger discriminable frequency increment $(\Delta \mathrm{f}=\sim 20 \mathrm{~Hz})$ than lower frequencies (at $20 \mathrm{~Hz}, \Delta \mathrm{f}=\sim 5 \mathrm{~Hz}$ ), particularly for the fingertip and forearm $[15,33]$. In this study, the Ruffini cylinders and Pacinian corpuscles in the upper thigh were targeted around the anterior, posterior, lateral, and medial regions by stimulating at frequencies that were higher $(140,180$, and $220 \mathrm{~Hz})$ than those previously investigated by Wentink et al. $(30-80 \mathrm{~Hz})$ [15] so as to better match the response frequency range of Ruffini cylinders and Pacinian corpuscles $(60-400 \mathrm{~Hz})$.

From the four locations tested around the thigh, the anterior location resulted in quicker RTs than the lateral, medial, and posterior regions. From the literature, three main nerves of interest within the thigh region interact with the skin mechanoreceptors to relay information back to the peripheral and central nervous system. These are primarily the anterior femoral cutaneous nerve, lateral 
Table 2.

Summary of main attributes for each of four mechanoreceptors found in skin.

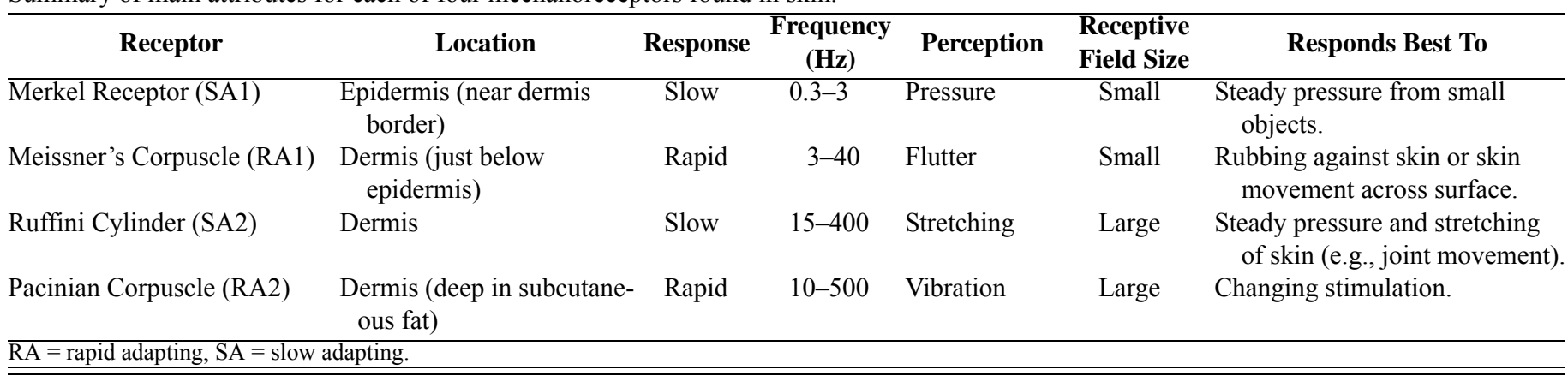

femoral cutaneous nerve, and posterior femoral cutaneous nerve [29]. From nerve conduction studies of the cutaneous femoral nerves, researchers have been able to quantify conduction velocity of some of these nerves. This conduction velocity is the speed an impulse travels along a nerve [35], and it has been shown that the anterior femoral cutaneous nerve has a faster conduction speed than the lateral and posterior femoral cutaneous nerves. While this corroborates with our findings in that the anterior location resulted in the fastest RT, it only partially explains the differences since the conduction time differences are much smaller [36-38] than the RT differences found here that are on the order of $100 \mathrm{~ms}$.

The longest part of the RT is attributed to the time it takes the brain to process the information and to plan a motor response. This time increases in the case when multiple stimuli are presented or when there is uncertainty about the stimulus that is forthcoming. This is commonly referred to as "Hick's law," which states that as the number of stimuli-response alternatives increase, RTs also increase in a linear form [39].

The aforementioned is important to consider since a practical feedback system may need to provide multiple inputs while still eliciting responses in a timely manner. For the balance-augmenting biofeedback system by Rusaw et al., the group utilized multiple pressure sensors at the various locations on the plantar foot to provide information on foot loading; this multichannel information was relayed to multiple stimulators at the residuum [8]. Similarly, in upper-limb prosthetic applications, the systems typically comprise multiple signals to effectively relay sensory information from the prosthetic hand back to the user [40]. In this study, we examined several aspects relating to multisignal sensory feedback, including (1) providing stimuli via multiple vibrators that are located in close proximity to each other (i.e., spatial resolution) and (2) providing multiple signals via a single stimulator simply by changing the frequency. In general, having stimuli too close together, either physically or characteristically, impedes the decision-making process and ultimately slows RTs. Response accuracy is also affected by the way stimuli are provided. Specifically, providing multiple inputs via two individual motors produced higher accuracy than via a single motor at two frequencies.

The final factor affecting RT is dictated by the time it takes for the brain to send motor signals and for the muscles to respond and generate a movement. The present study compared the RTs between the upper and lower limbs and found the latter to be significantly longer. A number of factors are likely at play, including differences in the neurophysiology and physiology of the muscles, as well as the inertial characteristics of the involved anatomy, whereby the higher mass of the leg could lead to higher acceleration times $[35,41]$. It should be noted that while it is interesting to examine the differences in RTs between the hand and thigh, corrective actions during mobility would likely be effective only when initiated within the lower limbs (instead of the upper limbs), so it remains of a primary interest to consider the sensorimotor responses associated with the lower limbs.

One of the limitations of this study is that the amplitude and frequency of the vibratory motors were coupled. Specifically, based on the manufacturers' data sheets, for the tested frequencies of 140,180 and $220 \mathrm{~Hz}$, the corresponding vibration amplitudes were $1.22,1.58$, and $1.92 \mathrm{~g}$, respectively. In future studies, frequency and amplitude should be independently controlled and retested to validate the results of this study. Also, in this study the motors were precalibrated to produce a specific frequency at a certain voltage, but it was not possible to confirm that this frequency was maintained when the motors were applied to the participant's skin. It should 
also be noted that the actuation period of the motors to bring them to full speed adds a slight delay to the system, and therefore, the RTs. We tested this delay, measured as the time it took the motor to reach full speed (measured by an accelerometer) from the time a voltage was applied. The duration of the delay was, on average, $25 \mathrm{~ms}$. Other limitations include the variability in the study participants, especially in the individuals with LLA. Some of these include factors such as age, BMI, and cause of amputation (congenital vs acquired), which could not be examined in detail here due to the small sample size. Also, all of the participants performed the experiments with limited training, whereas in an application such as an artificial feedback system, the user's sensorimotor RTs may be expected to decrease with use over the long-term.

\section{CONCLUSIONS}

Providing artificial sensory feedback may be a useful way of improving the mobility function of people with LLA, but limited information is available to inform the design and development of such systems. In this study, we investigated the sensorimotor response of individuals in a way that would potentially make it applicable to prosthetic mobility rehabilitation. The findings suggest that certain approaches may be utilized to shorten RT and increase accuracy. However, despite this, the feasibility and effectiveness of artificial feedback systems for gait may still be in question due to relatively long RTs. Further work should examine more sophisticated control strategies, e.g., those used in feed-forward systems.

\section{ACKNOWLEDGMENTS}

\section{Author Contributions:}

Study concept and design: A. Sharma, J. Andrysek.

Acquisition, analysis, and interpretation of data: A. Sharma, J. Andrysek.

Drafting of manuscript: A. Sharma, J. Andrysek.

Critical revision of manuscript for important intellectual content:

J. Andrysek, K. Zabjek, R. Torres-Moreno.

Statistical analysis: A. Sharma, J. Andrysek.

Obtained funding: J. Andrysek.

Study supervision: J. Andrysek, K. Zabjek, R. Torres-Moreno.

Financial Disclosures: The authors have declared that no competing interests exist.
Funding/Support: This material was based on work supported by the Natural Sciences and Engineering Research Council of Canada (grant RGPIN 401963).

Additional Contributions: Mr. Sharma is now with the Department of Veterans Affairs, Martinsburg, West Virginia.

Institutional Review: The Research Ethics Boards at Holland Bloorview Kids Rehabilitation Hospital and the University of Toronto approved this study for human subject testing, and informed written consent was obtained from each participant.

Participant Follow-Up: The authors plan to inform participants of the publication of this study.

\section{REFERENCES}

1. Fan RE, Culjat MO, King CH, Franco ML, Boryk R, Bisley JW, Dutson E, Grundfest WS. A haptic feedback system for lower-limb prostheses. IEEE Trans Neural Syst Rehabil Eng. 2008;16(3):270-77. [PMID:18586606] http://dx.doi.org/10.1109/TNSRE.2008.920075

2. Dickinson J. Proprioceptive control of human movement. Princeton (NJ): Princeton Book Co; 1976.

3. Delforge G. Musculoskeletal trauma: Implications for sports injury management. Champaign (IL): Human Kinetics; 2002.

4. Lephart S. Reestablishing proprioception, kinesthesia, joint position sense, and neuromuscular control in rehabilitation. In: Prentice WE, editor. Rehabilitation techniques in sport medicine. 2nd ed. St. Louis (MO): Mosby; 1994.

5. Liao KI, Skinner HB. Knee joint proprioception in belowknee amputees. Am J Knee Surg. 1995;8(3):105-9. [PMID:7552605]

6. Eakin CL, Quesada PM, Skinner H, Eakin. Lower-limb proprioception in above-knee amputees. Clin Orthop Relat Res. 1992;(284):239-46. [PMID:1395300]

7. Dozza M, Horak FB, Chiari L. Auditory biofeedback substitutes for loss of sensory information in maintaining stance. Exp Brain Res. 2007;178(1):37-48.

[PMID:17021893] http://dx.doi.org/10.1007/s00221-006-0709-y

8. Rusaw D, Hagberg K, Nolan L, Ramstrand N. Can vibratory feedback be used to improve postural stability in persons with transtibial limb loss? J Rehabil Res Dev. 2012; 49(8):1239-54. [PMID:23341316] http://dx.doi.org/10.1682/JRRD.2011.05.0088

9. Geurts AC, Mulder TW, Nienhuis B, Rijken RA. Dual-task assessment of reorganization of postural control in persons with lower limb amputation. Arch Phys Med Rehabil. 1991;72(13):1059-64. [PMID:1741657]

10. Geurts AC, Mulder TW, Nienhuis B, Rijken RA. Postural reorganization following lower limb amputation. Possible motor and sensory determinants of recovery. Scand J Rehabil Med. 1992;24(2):83-90. [PMID:1604266] 
11. Geurts AC, Mulder TH. Attention demands in balance recovery following lower limb amputation. J Mot Behav. 1994;26(2):162-70. [PMID:15753068] http://dx.doi.org/10.1080/00222895.1994.9941670

12. Gailey RS, Wenger MA, Raya M, Kirk N, Erbs K, Spyropoulos P, Nash MS. Energy expenditure of trans-tibial amputees during ambulation at self-selected pace. Prosthet Orthot Int. 1994;18(2):84-91. [PMID:7991365]

13. Miller WC, Speechley M, Deathe B. The prevalence and risk factors of falling and fear of falling among lower extremity amputees. Arch Phys Med Rehabil. 2001;82(8): 1031-37. [PMID:11494181] http://dx.doi.org/10.1053/apmr.2001.24295

14. Fan RE, Wottawa C, Mulgaonkar A, Boryk RJ, Sander TC, Wyatt MP, Dutson E, Grundfest WS, Culjat MO. Pilot testing of a haptic feedback rehabilitation system on a lowerlimb amputee. Proceedings of the 2009 ICME International Conference on Complex Medical Engineering; 2009 Apr 9-11; Tempe, AZ. p. 1-4.

15. Wentink E, Mulder A, Rietman JS, Veltink PH. Vibrotactile stimulation of the upper leg: Effects of location, stimulation method and habituation. Proceedings of the 2011 Annual International Conference of the IEEE Engineering in Medicine and Biology Society; 2011 Aug 30-Sep 3; Boston, MA. p. 1668-71.

16. Gauthier-Gagnon C, Grisé MC, Potvin D. Enabling factors related to prosthetic use by people with transtibial and transfemoral amputation. Arch Phys Med Rehabil. 1999; 80(6):706-13. [PMID:10378500] http://dx.doi.org/10.1016/S0003-9993(99)90177-6

17. Göktepe AS, Cakir B, Yilmaz B, Yazicioglu K. Energy expenditure of walking with prostheses: Comparison of three amputation levels. Prosthet Orthot Int. 2010;34(1): 31-36. [PMID:20196687] http://dx.doi.org/10.3109/03093640903433928

18. Freitas SM, Wieczorek SA, Marchetti PH, Duarte M. Agerelated changes in human postural control of prolonged standing. Gait Posture. 2005;22(4):322-30.

[PMID:16274914]

http://dx.doi.org/10.1016/j.gaitpost.2004.11.001

19. Levine D, Richards J, Whittle MW. Whittle's gait analysis. Edinburgh (UK): Churchill Livingstone/Elsevier; 2012.

20. Asseman F, Bronstein AM, Gresty MA. Effectiveness of a vibro-tactile feedback to cue a stepping response to a balance challenge. Proceedings of the 2006 IEEE International Workshop on Haptic Audio Visual Environments and Their Applications; 2006 Nov 4-5; Ottawa, Canada. p. 2-4.

21. Asseman F, Bronstein AM, Gresty MA. Using vibrotactile feedback of instability to trigger a forward compensatory stepping response. J Neurol. 2007;254(11):1555-61.

[PMID: 17641814]

http://dx.doi.org/10.1007/s00415-007-0587-7
22. Etnyre B, Kinugasa T. Postcontraction influences on reaction time. Res Q Exerc Sport. 2002;73(3):271-81.

[PMID:12230333]

http://dx.doi.org/10.1080/02701367.2002.10609020

23. Luchies CW, Schiffman J, Richards LG, Thompson MR, Bazuin D, DeYoung AJ. Effects of age, step direction, and reaction condition on the ability to step quickly. J Gerontol A Biol Sci Med Sci. 2002;57(4):M246-49. [PMID:11909891] http://dx.doi.org/10.1093/gerona/57.4.M246

24. Rose SA, Feldman JF, Jankowski JJ, Caro DM. A longitudinal study of visual expectation and reaction time in the first year of life. Child Dev. 2002;73(1):47-61.

[PMID:14717243]

http://dx.doi.org/10.1111/1467-8624.00391

25. Deary IJ, Der G, Ford G. Reaction times and intelligence differences: A population-based cohort study. Intelligence. 2001;29(5):389-99. http://dx.doi.org/10.1016/S0160-2896(01)00062-9

26. Schaie KW, Willis SL, Knight BG, Levy B, Park DC. Handbook of the psychology of aging. Amsterdam (the Netherlands): Elsevier/Academic Press; 2011.

27. Bellis CJ. Reaction time and chronological age. Exp Bio Med (Maywood). 1933;30(6):801-3. http://dx.doi.org/10.3181/00379727-30-6682

28. Engel BT, Thorne PR, Quilter RE. On the relationships among sex, age, response mode, cardiac cycle phase, breathing cycle phase, and simple reaction time. J Gerontol. 1972;27(4):456-60. [PMID:5075489] http://dx.doi.org/10.1093/geronj/27.4.456

29. Agur AM, Dalley AF, Grant JC. Grant's atlas of anatomy. 13th ed. Philadelphia (PA): Wolters Kluwer Health; 2012.

30. Bolanowski SJ Jr, Gescheider GA, Verrillo RT, Checkosky CM. Four channels mediate the mechanical aspects of touch. J Acoust Soc Am. 1988;84(5):1680-94.

[PMID:3209773]

http://dx.doi.org/10.1121/1.397184

31. Cholewiak RW. The perception of tactile distance: Influences of body site, space, and time. Perception. 1999;28(7): 851-75. [PMID:10664778]

http://dx.doi.org/10.1068/p2873

32. Kandel ER, Schwartz JH, Jessell TM. Principles of neural science. 4th ed. New York (NY): McGraw-Hill, Health Professions Division; 2000.

33. Mahns DA, Perkins NM, Sahai V, Robinson L, Rowe MJ. Vibrotactile frequency discrimination in human hairy skin. J Neurophysiol. 2006;95(3):1442-50. [PMID:16319219] http://dx.doi.org/10.1152/jn.00483.2005

34. Verrillo RT. Psychophysics of vibrotactile stimulation. J Acoust Soc Am. 1985;77(1):225-32. [PMID:3882801] http://dx.doi.org/10.1121/1.392263 
35. Cuccurullo SJ. Physical medicine and rehabilitation board review. 2nd ed. New York (NY): Demos Medical; 2009.

36. Lee HJ, Bach JR, DeLisa JA. Medial femoral cutaneous nerve conduction. Am J Phys Med Rehabil. 1995;74(4): 305-7. [PMID:7632388]

http://dx.doi.org/10.1097/00002060-199507000-00008

37. Butler ET, Johnson EW, Kaye ZA. Normal conduction velocity in the lateral femoral cutaneous nerve. Arch Phys Med Rehabil. 1974;55(1):31-32. [PMID:4809016]

38. Brooks JBB, Silva C, Kai MR, Leal GX. Electrophysiological study of the posterior cutaneous femoral nerve: Normative data. J Neurol Neurophysiol. 2011;2:119. http://dx.doi.org/10.4172/2155-9562.1000119

39. Longstreth LE, el-Zahhar N, Alcorn MB. Exceptions to Hick's law: Explorations with a response duration measure. J Exp Psychol Gen. 1985;114(4):417-34. [PMID:2934496] http://dx.doi.org/10.1037/0096-3445.114.4.417

40. Blank A, Okamura AM, Kuchenbecker KJ. Identifying the role of proprioception in upper-limb prosthesis control: Studies on targeted motion. ACM Trans Appl Percept. 2010;7(3):1-19. http://dx.doi.org/10.1145/1773965.1773966

41. Anzola GP, Bertoloni G, Buchtel HA, Rizzolatti G. Spatial compatibility and anatomical factors in simple and choice reaction time. Neuropsychologia. 1977;15(2):295-302.

[PMID:846638]

http://dx.doi.org/10.1016/0028-3932(77)90038-0

Submitted for publication July 18, 2013. Accepted in revised form February 27, 2014.

This article and any supplementary material should be cited as follows:

Sharma A, Torres-Moreno R, Zabjek K, Andrysek J. Toward an artificial sensory feedback system for prosthetic mobility rehabilitation: Examination of sensorimotor responses. J Rehabil Res Dev. 2014;51(6):907-18.

http://dx.doi.org/10.1682/JRRD.2013.07.0164

ResearcherID/ORCID: Aman Sharma, MHSc: C-27382013

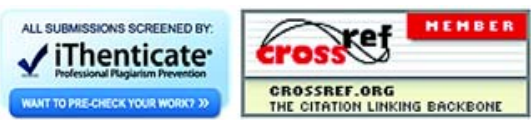

